\title{
PERCEPÇÃO DA RELAÇÃO TEORIA E PRÁTICA NO TRABALHO DOCENTE: um estudo com professores da área da saúde
}

\section{D.D.F.SOUZA*, M.J.F. TORRES ${ }^{*}$ e S.F.DANTAS*}

Instituto Federal de Educação, Ciência e Tecnologia do Rio Grande de Norte dalvanira.df@gmail.com, mjft06@gmail.com, silvaniafrandantas@gmail.com

Artigo submetido em janeiro/2017 e aceito em abril/2017

DOI: $10.15628 /$ rbept.2017.5732

\section{RESUMO}

Este trabalho apresenta uma pesquisa feita em instituições de ensino de Educação profissional de nível técnico com docentes da área em atuação sobre a construção das relações entre teoria e prática na formação de professores. Como técnica de coleta de dados utilizamos a entrevista semi-estruturada, composta de 04 (quatro) questões do tipo aberta aplicada a 06 seis professores técnicos da área de saúde. Em seguida, fizemos as transcrições de suas falas para a análise de suas percepções acerca da relação teoria e prática no contexto do processo de ensinoaprendizagem em sala de aula. Para o embasamento teórico, buscamos autores como Moura, (2008), Kuenzer (2008) Moll (2010). O objetivo desta pesquisa foi identificar a percepção do docente em relação à teoria e prática em sala de aula nos cursos técnicos de enfermagem, Radiologia e Analises Clínicas. No sentido de trazer reflexões acerca desta temática, perguntamonos como ocorre a relação teoria e prática na docência da Educação Profissional?. - Na sua percepção, como se dá a relação teoria e prática no processo de ensino e aprendizagem?. Existem elementos nas matrizes curriculares dos cursos, técnico de Enfermagem, Radiologia e Análises Clínicas onde você atua, que fazem a interconexão entre teoria e prática? Que experiências, você, como docente, desenvolve com seus estudantes para concretizar a articulação entre teoria e prática?. Por fim, fizemos a análise das transcrições e percebemos como resultado que a maioria dos entrevistados acreditam que a relação teoria e prática na formação docente na educação profissional são essenciais e que a prática depende da teoria, bem como a teoria depende daprática.

PALAVRAS-CHAVE: Docência, Teoria e Prática, Educação Profissional, Ensino e aprendizagem.

\section{RELATIONSHIP OF PERCEPTION THEORY AND PRACTICE IN THE TEACHING PROFESSION: a study of the health of teacher}

\section{ABSTRACT}

This paper presents a survey of some professional education of educational institutions technical level with area teachers at work on the construction of the relationship between theory and practice in teacher education. Date collection technique used a semistructured interview consisting of four (04) open type questions applied to 06 six technical teachers of health. Then we made the transcripts of their speeches to the analysis of their perceptions about the relationship between theory and practice in the context of the teaching-learning process in the classroom. For the theoretical framework, we seek to authors such as Moura (2008), Kuenzer (2008) Moll (2010). The objective of this research was to identify the perception of teachers in relation to the theory and practice in the classroom in technical courses in nursing, Radiology and Clinical Analyses. In order to bring reflections on this issue, we wonder how does the relationship between theory and practice in the teaching of Vocational Education?. In your view, how is the relationship between theory and practice in teaching and learning? There are elements on curricular courses, nursing technician, Radiology and Clinical Analysis where you operate, which make the interconnection between theory and practice? What experiences have you, as a teacher, develops their students to achieve the articulation between theory and practice?. Finally, we made the analysis of transcripts and realized as a result that the majority of respondents believe that the relationship between theory and practice in teacher training in vocational education are essential and that the practice depends on the theory and the theory depends on practice.

KEYWORDS: Teaching. Theory and Practice, Professional Education, Teaching. Learning. 


\section{INTRODUÇÃO}

O trabalho aqui exposto foi desenvolvido no Programa de Pós-Graduação em Educação Profissional do Instituto Federal de Educação, Ciências e Tecnologia do Rio Grande do Norte, tendo como docentes responsáveis as professoras doutoras, Ana Lúcia Sarmento Henrique e Ilane Ferreira Cavalcante, da disciplina Formação de professores para a educação profissional.

A pesquisa teve como objetivo geral identificar a percepção docente em relação a teoria e prática na atuação docente, em instituições particulares de ensino técnico de nível médio na área da saúde.

Nesse artigo, iremos analisar, a partir de uma entrevista semi-estruturada, a percepção dos docentes de disciplinas de formação geral e específicas, com ênfase na sua formação profissional, tendo como eixo principal a relação teoria e prática na atuação docente, nas instituições investigadas de ensino, denominadas de Instituição de Ensino 01- I E01 e Instituição de Ensino 02 - IE02, nos Cursos técnicos de Enfermagem - CE, de Radiologia - CR e de Análises Clínicas - CAC.

\section{REVISÃO BIBLIOGRÁFICA}

No transcurso da história, a Educação Profissional no Brasil foi embasada por muitas teorias, aplicadas nas mais diversas práticas pedagógicas, sofrendo mudanças na sua estrutura através de políticas educacionais voltadas para os interesses capitalista, atendendo a produção de mão de obra qualificada. Koller e Sobral (2010, p,226), registram momentos importantes da história quando foram deflagradas as reformas educacionais, em 1968 a Reforma Universitária e em 1971 a Reforma do Ensino do 10 e 2ㅇ graus, quando onde apresenta uma proposta de equalização social por intermédio de um discurso de valorização da educação com vistas a propiciar a todos uma igualdade de oportunidades perante o mercado de trabalho. Nesse sentido, Giron $(2012$, p 5$)$

A educação, nos diferentes momentos históricos, manteve-se intimamente ligada a uma visão social, ou seja, foi usada para se ganhar espaço e projeção na sociedade. Hoje, quem tem acesso à educação tem maior possibilidade de se inserir no mercado de trabalho. Entretanto, a educação raramente se manifesta como um fim em si mesmo: ou é usada como instrumento de manutenção de certa ordem social e econômica, ou serve como meio de transformação dessa estrutura. Parafraseando Freire (1991) não existe 
neutralidade na educação, como não existe neutralidade em nenhuma ação humana: ou se está atuando a favor ou contra certa ideologia. (GIRON, 2012).

\subsection{A RELAÇÃo tEORIA E PRÁtICA DOCENTE NO PROCESSO DE ENSINO E APRENDIZAGEM NA EDUCAÇÃO PROFISSIONAL DA ÁREA DE SAÚDE.}

A educação profissional em todas as áreas se constitui num processo formativo pelo qual os futuros trabalhadores são formados para produzirem sua existência por meio do trabalho, o qual se volta para a produção de bens e serviços necessários e socialmente reconhecidos pela sociedade. (Ramos, 2013). Dentre os processos de formação profissional, destacamos, neste estudo, a formação de professores para a área da saúde numa perspectiva de formação humana integral, pois ainda existe uma relação muito estreita entre trabalho e formação humana no sentido de saber como esse ser humano vai ser inserido no mundo do trabalho e nas práticas sociais.

Pensar em educação, implica numa questão para toda a sociedade - a qualidade da educação que é oferecida. Na educação profissional, um dos elementos a ser refletido é a relação teoria e prática no ofício do ensinar o outro a aprender. Para uma melhor compreensão dessa relação, convém compreender o significado desses termos. De acordo com Candau (1999, p.58), os termos teoria e prática vêm do grego. Teoria deriva do termo grego "Theoría" significava originalmente a viagem de uma missão festiva aos lugares do sacrifício. E a 'prática' deriva do grego "práxis", "práxeos", e tem o sentido de agir.

A autora (1999, p.58), acrescenta que, as formas de conceber a relação teoria e prática são muitas. No entanto, acreditamos poder agrupá-las, fundamentalmente, em dois esquemas a visão dicotômica e a visão de unidade. Nesse sentido, a prática é o resultado da teoria, ou seja, a prática não cria, a inovação se dá por meio da teoria. Na visão da unidade entre ambas, o foco é a união entre teoria e prática, essa união é simultânea e recíproca.

Moura, (2008, p. 205) nos afirma que "para afrontar a realidade vigente com eficiência e responsabilidade social", os professores, técnico administrativos e dirigentes das instituições de Educação Profissional Técnica - EPT, principais sujeitos envolvidos juntamente com os estudantes, necessitam ser muito bem formados e qualificados profissionalmente. Nesse processo educativo, o professor deve assumir outro tipo de formação, que deve ser crítica e reflexiva e orientada pela responsabilidade social. Alarcão (2001, p.06), acrescenta, "ser capaz de 
se organizar para, perante uma situação problemática se questionar intencional e sistematicamente com vista à compreensão e posterior solução".

\subsection{ARTICULAÇÃO TEORIA E PRÁTICA DOS ELEMENTOS DA MATRIZ CURRICULAR}

Consideramos que currículo é visto como uma expressão dinâmica, por existir um ritmo de compreensão e assimilação dos conteúdos que devem ser trabalhados na escola. Diante do exposto, a autora abaixo nos relata que:

\footnotetext{
O currículo é uma prática socialmente construída e historicamente formada. Ele envolve o conjunto das experiências planificadas proporcionadas pela escola tendo em vista a concretização dos objetivos da aprendizagem. Não é algo estático vinculado somente a conhecimentos que se deseja transmitir. Envolve também, práticas políticas e administrativas, condições estruturais, materiais e a formação dos educadores. (MACHADO, 2010, p.94).
}

Nesta perspectiva, ampliamos este entendimento de currículo para os cursos técnicos de ensino médio na área da saúde, onde a formação dos seus docentes, além dos seus saberes técnicos específicos de cada área, seja somado aos saberes didáticos. Importante ressaltar que o conteúdo formador e sua experiência pessoal o instrumentalizam ao exercício profissional garantindo a articulação entre o teórico e o prático.

A Lei 9394/96, que instituiu as bases e formas de organização da educação no Brasil, sofreu modificações com a Lei no 11.741 , de 2008, que altera dispositivos, estabelecendo as diretrizes e bases da educação nacional, para redimensionar, institucionalizar e integrar as ações da educação profissional técnica de nível médio, da educação de jovens e adultos e da educação profissional e tecnológica. No art. 36-A. Parágrafo único diz que:

\footnotetext{
A educação profissional técnica de nível médio deverá observar: o item I - os objetivos e definições contidos nas diretrizes curriculares nacionais estabelecidas pelo Conselho Nacional de Educação; art 36-D. "Parágrafo único. Os cursos de educação profissional técnica de nível médio, nas formas articulada, concomitante e subsequente, quando estruturados e organizados em etapas com terminalidade, possibilitarão a obtenção de certificados de qualificação para o trabalho após a conclusão, com aproveitamento, de cada etapa que caracterize uma qualificação para o trabalho. (BRASIL,1996).
}

Portanto, currículo é um processo dinâmico que se propõe a assegurar sua eficiência para atingir os objetivos propostos no ensino e aprendizagem.

\subsection{A IMPORTÂNCIA DA UTILIZAÇÃO DA APLICABILIDADE DO CONHECIMENTO TEÓRICO E PRÁTICO NA FORMAÇÃO DOCENTE NA EDUCAÇÃO PROFISSIONAL}


O saber docente não é formado apenas pela prática, mas também pela teoria. A teoria tem fundamental importância, com ela nos aprofundamos do conhecimento para pormos em prática o que foi discutido em sala de aula. É na prática que encontramos nossas reais dificuldades e, assim, buscamos com a aplicabilidade melhorar a formação.

Desse modo, compreendemos que o trabalho docente não se constitui apenas da teoria, a aplicabilidade do conhecimento prático é essencial na formação profissional. Pois, a aproximação entre teoria e prática nos mostram novos horizontes que nos possibilitam buscar diversas práticas de ensino que facilitem a aprendizagem dos educandos.

Assim, o educador somente poderá ensinar quando aprender na prática o que deve fazer e, para isso, ter conhecimento, que é adquirido com diálogo e troca de experiências. Compreender o processo de ensino e aprendizagem, apesar da formação oferecida em sala de aula ser fundamental, só ela não é suficiente para preparar os alunos para o exercício de sua profissão. Faz-se necessário a inserção na realidade do cotidiano escolar com a prática pedagógica.

O docente ao se apropriar do conhecimento prático e teórico vence as dificuldades e vê com clareza as novas possibilidades de reflexão e crítica sobre as práticas.

Na educação profissional não é diferente no que diz respeito à aplicabilidade da teoria e prática na formação docente. Com a prática, o professor percebe como vem sendo feito seu trabalho, e com isso, busca as melhores possibilidades para se adquirir uma melhor formação profissional. Em concordância a isso, Kuenzer nos mostra que:

\footnotetext{
Exige-se uma formação de um novo tipo de professor da Educação Profissional e Tecnológica, capaz de criar situações de aprendizagem nas quais o jovem desenvolva a capacidade de trabalhar intelectualmente, a partir do que se capacita para enfrentar as situações da prática social e do trabalho (KUENZER, 2008, p. 28).
}

São situações de aprendizagem desenvolvidas na teoria e aplicadas na prática que o docente torna-se capaz de melhorar através do exercício de sua profissão.

Quanto à Educação Profissional, esta foi regulamentada através da nova LDB 1996 (Lei de Diretrizes e Bases para a Educação). Conforme o artigo 39 da mencionada lei: "a educação profissional, integrada às diferentes formas de educação, ao trabalho, à ciência e à tecnologia" conduz ao "permanente preparo para o trabalho e para a vida produtiva" 
Diante disso, vale ressaltar que a educação profissional é um tema que vem sendo discutido na sociedade brasileira. Nesse período, iniciam-se discussões a respeito da formação docente. Essas discussões vêm sendo ampliadas graças a um conjunto de reformas educacionais que contribuem para essa temática, conforme podemos observar que:

A educação profissional e tecnológica é um tema que desde meados dos anos de 1990 vem ganhando destaque na pesquisa educacional no Brasil, face à proposição e implementação de um amplo conjunto de reformas educacionais e ao estabelecimento de diversas políticas públicas e programas governamentais relacionados à temática. (MOLL, 2010 p.141).

Desse modo, observa-se uma discussão teórica que fortalece a importância dessa incessante busca de conhecimento do professor atuante na educação profissional.

Isso evidencia que, para a apropriação da produção de conhecimento na área da educação profissional, o docente necessita de uma capacitação que o torne apto à prática do ensino, bem como, relacionar isso à formação de profissionais que além das habilidades técnicas e da qualificação profissional, é preciso ter um bom desempenho no que se refere às habilidades relacionadas ao comportamento ético e de boas práticas na convivência cidadã. Sendo assim:

\begin{abstract}
A formação pedagógica para os profissionais que atuam ou atuarão como professores do conteúdo específico da Educação Profissional Tecnológica, exige em primeiro lugar, das instituições que se dispuserem a esta atribuição, o comprometimento com o fortalecimento de uma cultura do valor do trabalho educativo enquanto aspecto que deve perpassar os diferentes fazeres da escola e que se paute pela permanente reflexão sobre o sentido do porquê fazemos educação neste país, algo que certamente contribuirá para modificar o perfil do profissional não só docente, mas também os técnicos administrativos que atuam na Educação Profissional Tecnológica. (PEREIRA, [s.d], p.6).
\end{abstract}

Diante disso, a prática da educação permanente para o aperfeiçoamento dos docentes e a formação do funcionário de escola, na sua especificidade, contribui para seu aperfeiçoamento profissional e também o instrumentaliza para a participação política na escola e fora dela, possibilitando superar o entendimento de que, os profissionais administrativos ou outras categorias profissionais, são meros executores de tarefas escolares, tornando-os conscientes de seu papel de agentes ativos na realização da função social da educação escolar.

Nessa direção, Machado (2008, p.18) afirma, que “o professor da Educação Profissional deve ser capaz de permitir que seus alunos compreendam, de forma reflexiva e crítica, os mundos do trabalho, dos objetos e dos sistemas tecnológicos dentro dos quais eles evoluem", ou 
seja, o professor deve criar uma correspondência sobre: o quê, o para quê e quem estão envolvidos na finalidade do ensino aprendizagem.

Segundo a mesma autora:

O perfil do profissional docente da educação profissional engloba, além das especificidades das atividades pedagógicas relativas ao processo de ensinoaprendizagem neste campo, as dimensões próprias do planejamento, organização gestão e avaliação desta modalidade educacional nas suas íntimas relações com as esferas da educação básica. (MACHADO, 2008 p.18).

Observa-se dessa forma, que o professor da educação profissional necessita ter um amplo conjunto de conhecimentos que contribuam para trabalhar e dialogar com diferentes campos de conhecimentos para que possa, assim, inserir sua prática educativa no contexto social. Isso leva a entender que o docente na Educação Profissional necessita ir além dos conhecimentos específicos da disciplina. Devido a isso, é imprescindível o trabalho com diferentes formas de realizações da transposição didática dos conteúdos específicos, considerando dessa maneira a complexidade apresentada por esta modalidade educacional.

Ainda sob esse prisma, a formação docente na Educação Profissional, a autora nos mostra que:

\footnotetext{
Os professores da educação profissional enfrentam novos desafios relacionados às mudanças organizacionais que afetam as relações profissionais, aos efeitos das inovações tecnológicas sobre as atividades de trabalho e culturas profissionais, ao novo papel que os sistemas simbólicos desempenham na estruturação do mundo do trabalho, ao aumento das exigências de qualidade na produção e nos serviços, à exigência de maior atenção à justiça social, às questões éticas e de sustentabilidade ambiental. (MACHADO, 2008, p.15).
}

Nesse contexto, compreendemos que os docentes da educação profissional estão sempre encontrando novos desafios para a sua prática pedagógica tendo em vista que as inovações estão sendo cada vez mais presentes na formação docente.

\section{METODOLOGIA}

Em termos metodológicos, a pesquisa foi desenvolvida junto aos alunos da disciplina de Formação de Professores para a Educação Profissional, do Programa de Pós-graduação no Mestra do Acadêmico em Educação Profissional do IFRN. 
As questões para a entrevista foram elaboradas por todos os alunos em conjunto com as professoras Ana Lúcia Sarmento Henrique e Ilane Ferreira Cavalcante no decorrer das aulas. As perguntas foram organizadas conforme o eixo estruturante de cada área, e em seguida, os grupos realizaram as entrevistas nas instituições determinadas. Nossa pesquisa, como já ressaltamos, foi feita nas Instituições de Ensino IE-01 e IE-02, nos Cursos de Enfermagem (CE), Radiologia (CR) e Análises Clínicas (CAC).

Os sujeitos da pesquisa são 06 professores da rede privada em duas instituições de ensino técnico de nível médio na área da saúde, tanto de formação geral quanto da que atuam nos três cursos em foco.

Para o desenvolvimento da entrevista foram feitas de forma oral sendo utilizada como rec urso metodológico a utilização de um gravador para a gravação das falas. Em seguida foram realiz adas as transcrições das falas.

As categorias que nortearam a entrevista se voltaram para percurso formativo (inicial e continua do dos docentes) e para sua percepção do trabalho e do trabalho docente quanto à Relação teori a e prática na atuação docente. Na IE01 foram realizadas 04 entrevistas a 02 professores que atuam na área geral (PFG1 e PFG2) e a 02 professores que atuam na área especifica (PFE1 e PFE2) no curso Técnico Subsequente de Enfermagem - CE.

Na IE02 foram realizadas 06 entrevistas a 02 professores que atuam na área geral (PFG1 e PFG2) e a 04 professores que atuam na área especifica (PFG1) no curso Técnico Subsequente e Subsequente Análises Clínicas (CAC) e Técnico Subsequente Radiologia (CR).

\subsection{CARACTERIZANDO OS LOCUS DE PESQUISA E DO CURSO}

Em fevereiro de 2016, os grupos foram às instituições IE-01 e IE-02, previamente agenda das e em concordância com as instituições, para fazerem a entrevista. Os grupos que foram fazer a entrevista levantaram a caracterização da instituição e do curso como também a área instalada.

No dia 16 de março de 2016, em sala de aula, os grupos apresentaram de forma sucinta a caracterização das instituições visitadas, depois ocorreu a socialização das entrevistas apresent ando suas dificuldades e como o processo de aplicação do questionário havia sido desenvolvido. Depois de realizada a divisão dos grupos para confecção do artigo, e definição da data de socializ ação das transcrições e da entrega do artigo.

A Instituição de Ensino - 01 - IE- 01 é uma instituição privada de ensino técnico de nível 
médio que atua com cursos na área da saúde Enfermagem, Análises Clínicas e Nutrição e Dietétic a, mais as especializações de áreas técnicas do eixo Higiene e Saúde.

Sua autorização de funcionamento se deu por intermédio da Portaria no 299/94, de 27 d e junho de 1994, com retroação dos seus efeitos a 1992. Funciona nos três turnos, matutino, ves pertino e noturno, em três unidades situadas no Rio Grande do Norte.

A estrutura física conta, com sede própria, com oito salas de aula climatizadas, um labor atório de informática, um laboratório para aulas práticas, um auditório com 60 lugares, uma bibli oteca, sala de direção administrativa, pedagógica, e financeira, professores, secretaria, recepção, banheiros, cantina, almoxarifado, minicopa e banheiros adaptados para necessidades especiais.

Os Recursos tecnológicos disponíveis nesses laboratórios permitem aulas teóricas e práti ca, desenvolvidas para os cursos ministrados no IE-01, em estratégia compartilhada com os profe ssores, que inclui a demonstração dos procedimentos pelo docente e posterior execução individu al por todos os discentes, a partir da divisão em grupos de alunos, com a presença de todos os pr ofessores e monitores da disciplina, além disso, mantém convênio com serviços de saúde público s e privados para os estágios supervisionados.A Instituição de Ensino - 02 - IE- 02 é uma instituiçã o privada de ensino técnico de nível médio que atua com cursos na área da Enfermagem Análise Clínicas, Radiologia dentre outros cursos.

A estrutura física conta, com sede própria, com salas de aula climatizadas, um laboratóri o de informática, um laboratório para aulas práticas, um auditório com 80 lugares, uma bibliotec a, sala de direção administrativa, pedagógica, e financeira, professores, secretaria, recepção, ban heiros, cantina, almoxarifado, e banheiros adaptados para necessidades especiais.

De forma democrática, os grupos foram formados para elaboração dos artigos de acordo com os eixos estruturantes, constituídos no roteiro da entrevista semi-estruturada.

O eixo de questionamento foi estruturado em três linhas de pesquisa, sendo o primeiro destinado ao percurso formativo contendo as seguintes formulações: qual a sua formação?; Você possui alguma formação para docência?; Há quanto tempo você atua com educação profissional? ; Há quanto tempo você leciona?; Em algum momento do seu processo formativo, a educação pr ofissional foi discutida?; "Por exemplo", você está trabalhando há 2 anos, lecionando na educaçã o profissional. Aqui ou em outra instituição que você já tenha trabalhado, vocês já se reuniram pa ra discutir a formação docente do professor?; Você teve experiências formativas para a docência que contribuíram para a articulação entre teoria e prática?; A instituição onde você atua tem pro porcionado situações de formação continuada para discutir as práticas docentes e/ou do process 
o de ensino e aprendizagem na Educação Profissional? Tem alguma situação em que vocês senta $m$ e discutem a formação continuada do professor?.

No segundo eixo, sobre a percepção de trabalho e trabalho docente as questões foram as seguintes: qual a sua concepção de trabalho?; Para você existe diferença entre trabalho docente e outros tipos de trabalho?; Há especificidades para atuação do professor no âmbito da educação profissional?; Qual o papel da educação profissional na formação dos sujeitos?.

Já no terceiro eixo, o foco da entrevista foi sobre a relação teoria $\mathrm{x}$ prática na atuação doc ente que são as seguintes: em sua percepção, como se dá a relação teoria x prática no processo d e ensino e aprendizagem?; Existem elementos na matriz curricular do curso, no caso sendo bem específico em Análises Clínicas, em que você atua que permitem a articulação entre teoria x práti ca? Como vocês chamam aqui: matriz curricular ou grade curricular?; Que experiências, você com o docente, desenvolve com seus estudantes para permitir a articulação entre teoria e prática? Aí são experiências mesmo, você pode citar algumas experiências.

Para a construção desse artigo foram utilizadas as questões abordadas no terceiro eixo. Concluindo a aplicação da entrevista teve prazo estabelecido para a socialização da transcrição q ue foi 23 de março de 2016 e entrega do artigo em 30 de abril de 2016.

\section{O QUE DIZEM OS PROFESSORES ENTREVISTADOS}

Este tópico tem como objetivo identificar o que dizem os docentes entrevistados, sobre a sua prática docente, a proposta presente no Projeto Político Pedagógico da instituição e sua concepção sobre a educação profissional.

Quanto à questão 11 procura-se identificar a percepção dos docentes entrevistados, sobre a relação teoria x prática no processo de ensino e aprendizagem. Como ver nos seguintes fragmentos:

[...] Essa questão de prática e teoria eu sempre digo que a teoria sem a prática ela não funciona, e nem a prática sem a teoria também não, as duas andam juntas. É preciso ter as duas para que se complemente. Então é impossível um sem o outro. ( IE-01 CE PFE 1).

[...] Na enfermagem não combina muito isso não. Porque você vai lidar com outro ser vivo, é uma pessoa, um ser humano, e é incoerente você dissociar a teoria da prática. Então, tanto deve ter a área teórica para ter o conhecimento, como deve ter a técnica. Então você vai juntar ambos, para a formação desse profissional. . ( IE-01 CE PFE 2).

[...] Não tem como separar a teoria da prática. Andam juntas. Então, precisa existir a teoria né, juntamente com a prática. Porque para eu poder executar uma técnica, eu 
preciso conhecer a teoria, o conhecimento. O que eu estou fazendo para aquele paciente. Entender aquilo ali que eu faço. Não só vale eu aprender a técnica, chegar lá e executar aquele procedimento, e aí? Eu não sei mais nada além daquilo ali? Então, não tem como dissociar. (IE-02 CAC PFE1).

[...] e eu preciso que esse técnico em análises clínicas ele tenha noção do que ele tá fazendo, eu preciso que ele saiba associar exatamente... é... a teoria com a prática. Ele precise ter o conjunto e não apenas dados isolados. Quando ele for fazer um processo de coleta sanguínea pra um hemograma, ele precise saber qual é a finalidade daquele exame... é... ele precise identificar as células que estão presentes alí e, quando ele for pra prática, ele precisa saber que ele não pode passar mais de dois minutos com o braço de um paciente garroteado porque ele causa a quebra das hemáceas e a quebra das hemáceas vão inabilitar o processo de leitura... é... pra o diagnóstico do meu paciente. Então a teoria e a prática, ela é essencial pra que eles tenham noção de trabalho. Então, quando eles saem da porta da escola pra fora e vão atuar, eles precisam ter a noção do que eles estão fazendo ali dentro, não só técnicos como técnicos, mas, sim, excelentes profissionais que tenham capacidade de associar teoria e prática pra o bom funcionamento do estabelecimento onde eles estão atuando. (IE-02 CAC PFE2).

[...] porém eu acredito que ainda um déficit de cobrança, não só aqui, mas geral, para que as respostas sejam mais positivas, pois a gente sabe que quem faz o aluno não é só o professor e a escola, a gente tem que ter um caráter pessoal de responsabilidade grande .Aqui na escola, por exemplo, eu dou disciplina específica para radiologia eu posso falar que ela é $100 \%$ prática e teórica, pois a gente une teoria e prática. IE-02 CR (PFE2).

De acordo com esse excerto, podemos dizer que esses professores percebem a relação teoria-pratica como uma relação de complementaridade e que uma não funciona sem a outra. Vala ressaltar que apesar de haver uma unanimidade sobre essa concepção, o professor IE-02 CAC PFE 2 conclui em uma de suas falas com a visão de que o trabalho realizado deve trazer visibilidade a instituição. Embora, compreendemos que o fundamental é o saber - fazer para a qualidade do processo de trabalho. Tal como afirmam as autoras Timoteo e Liberalino na citação a seguir:

\begin{abstract}
O entendimento atual de que o objetivo da escola não é apenas transmitir conteúdos disciplinares, mas o de desenvolver competências gerais nos alunos, traz, para o centro do debate, a necessidade de desconstruir o paradigma do conhecimento dicotomizado entre o saber e o fazer, entre a teoria e a prática, rumo à proposição (re)construtiva de um ensino aprendizado integrador e mobilizador de saberes e ações que remetam o aluno ao desenvolvimento do saber-fazer de alto nível(6). O conhecimento na ação, é fundamental para a ação humana diferenciada do saber fazer de baixo nível, o qual mobiliza apenas saberes limitados, do tipo procedimental, ou está representado por um repertório determinado de ações fundamentadas pelo hábito e geralmente permeadas de improvisação e espontaneidade. (TIMOTEO E LIBERALINO, 2003, p. 360).
\end{abstract}

As autoras ressaltam que o papel da escola não é apenas transmitir conteúdos disciplinares, mas o seu papel torna-se mais amplo como o de levar o aluno a um repensar a sua prática educativa. 
Já na questão 12 , o eixo de questionamento teve como base o conhecimento dos docentes sobre os elementos compostos na matriz curricular do curso da instituição em estudo sobre a articulação entre teoria e prática. Vejamos os comentários.

[...] Sim, aulas práticas. UTI também levamos os alunos para o laboratório e fazemos também aulas práticas. Biossegurança também nas ações de enfermagem. Então cada um com a sua, né? Todas tem práticas, simulações também nós fazemos. (IE01 CE PFE 1).

[...] Olha basicamente quase todas que eu aplico. Por exemplo, tem uma disciplina chamada Semiotécnica, então, é ... essa disciplina vai mostrar para o aluno, né? Os cuidados que eles deverão prestar assistência ao paciente. ...Então, isso não tem como fazer a distância, tem que ter a prática. (IE-01 CE PFE2).

[...] Sim. Como...né...Se é que eu estou entendendo aí, digamos assim, eu como enfermeira que ministro a aula no curso de Análises Clínicas é isso? Se na verdade, se minha formação permite, digamos assim, se eu como enfermeira atuar naquela disciplina, onde requer uma prática, a qual se não estiver, digamos assim, uma competência como profissional para poder executar a teoria e prática junto com aquele aluno. É isso? (IE-02 CAC PFE1).

[...] Então, a nossa grade curricular... é... nós temos as disciplinas específicas onde nós temos total liberdade pra... pra o manuseio tanto da teoria quanto da prática. Existe uma ementa onde exis... onde há o processo de solicitação, por exemplo, de determinadas práticas que o professor vai julgar se é cabível ou não. E aí o quê que acontece? A gente vai sempre tender a adaptar ao... a turma que a gente tem. Então às vezes eu tenho turma que são quinze alunos, tenho turmas que são oito alunos, mas eu tenho turma que são quarenta alunos, então eu preciso dosar o que é essencial no quesito "teoria e prática" pra que eles não saiam apenas imaginando como é que funciona, por exemplo, o processo... ham... de coleta, que é o carro chefe do processo de análises clínicas. (IE-02 CAC PFE2).

[...] Só lembro dos meus, na grade, na ementa, vem dizendo que de forma será, se será teórica e prática, desde as disciplinas de anatomia e fisiologia eles tem disciplinas teóricas e práticas, quando eles estão na prática são cobrados. (IE-02 CR PFE1).

Como podemos perceber, os entrevistados responderam que têm conhecimentos da proposta da política pedagógica da instituição referente a matriz curricular do curso. Porém, o entrevistado IE- 02 CAC PFE2, falou que faz a readaptação do conteúdo em sala de aula de acordo com a quantidade de alunos.

Logo em seguida, os entrevistados responderam à questão 13 sobre experiências, que como docente, desenvolve com seus estudantes para permitir a articulação entre teoria e prática. No fragmento abaixo, ele diz o seguinte:

[...] Se for em sala de aula, nós fazemos grandes círculos, não é? E nesses grandes círculos nós discutimos a teoria, logo após, nós vamos fazer as simulações. E se a aula é no laboratório, a exemplo, se for Semiotécnica, nós levamos os alunos para o laboratório, damos a aula de teoria, em sala, de aula e levamos os alunos para o laboratório para fazer o banho no leito a exemplo. Teoria em sala de aula, falando de teoria sobre punção venosa, levamos o aluno para o laboratório para fazer a punção venosa. Então sempre com essa complementação. ( IE-01 CE PFE 1). 
[...] Eu tenho vivência de hospital, trabalhei muitos anos em Unidade de Terapia Intensiva, fiz a especialização, a pós-graduação. Então assim, eu consigo passar para eles um pouco do que eu vivi, na minha experiência profissional antes da docência, né? Eu tive como adquirir essa prática, e fui aperfeiçoando, realizando curso superior e depois a pós-graduação. ( IE-01 CE PFE 2).

[...] Dependendo como falei da disciplina, por exemplo, digamos assim, ministrando a disciplina de Atendimento Hospitalar. Então é a questão da humanização nas ações de saúde, né?! Vários pontos são colocados. Então não tem como, digamos assim, até ministrar essa teoria sem trazer os fatos que são vivenciados. ( IE02 CAC PFE 1).

[...] Vamos lá! Os meus alunos... é... como eu tenho a... a formação técnica, então pra eles é muito mais... ham... vamos colocar assim, eles tem muito mais liberdade comigo pra fazer determinadas perguntas, por exemplo, é... quanto às dificuldades, quanto ao processo de rotina dentro de um laboratório, é... faixa salarial. E aí o quê que acontece? Nós temos um laboratório aqui que eu trago eles sempre pra tá executando as práticas e, sempre que possível, eu levo pra fazer visita técnica a um laboratório de verdade, a um... a um laboratório que tem toda estrutura onde eles vão conhecer o local de trabalho, e a partir dalí ele vai conhecendo uma bancada, ele vai conhecendo um exame de bioquímico, ele vai conhecendo os reagentes, vai tendo uma associabilidade com a... o futuro local de trabalho. Eles pagam estágio? Pagam estágio, mas quando eles chegam no estágio, eles já não chegam tão, vamos colocar assim, tão crus. Eles já chegam com uma noção de funcionamento de uma rotina laboratorial. ( IE-02 CAC PFE 2).

[...] Os exames de raio X. Existe uma descriminação por parte da marinha, em que lá a gente só ver mão, tórax, e etc. Entretanto lá eu vi de tudo e essa experiência que eu vivi lá eu trago para os alunos. Até o paciente que xinga você, que te esculhamba, até o paciente infantil, então eu sempre falo para os meus alunos. . (IE-02 CR PFE1).

Com base nas respostas apresentadas pelos participantes da pesquisa percebemos que a teoria e prática estão sempre presentes na formação de seus alunos, e que essa formação é imprescindível para a qualificação profissional. No entanto, fazemos referência que com base em algumas respostas dos entrevistados, estas, não atenderam ao questionamento feito pelo entrevistador.

Ficou evidente na fala do PFE2, ao afirma que, "é incoerente você desassociar a teoria da prática“. Diante dessa afirmação Candau \& Lelis (1999, p.60), na visão associativa, teoria e prática são polos separados, mas não opostos. Na verdade, estão justapostos.

A autora ainda acrescenta, que, "é importante lembrar também da dimensão integral da vida do educando; entendê-lo como alguém que, além de estudante, tem outros papéis no sistema das relações sociais". Diante desse contexto podemos dizer que o foco dessa concepção de currículo, é priorizar a integração dos saberes escolares com os saberes do cotidiano dos educandos, ou seja, um currículo integrado que seja capaz de atender a

\section{CONSIDERAÇÕES FINAIS}

A partir do exposto neste artigo, percebemos a importância da formação do professor, baseada na reflexão, sobre o conceito da teoria e prática para qualificação profissional. Diante 
disso, constatamos que a teoria é essencial para compreender a realidade que está inserida, mas essa compreensão se dará mediante a prática em sala de aula, quando o profissional irá confirmar de fato, como acontecem as relações de ensino aprendizagem.

Nesse cenário o docente busca aplicar a teoria na prática, muitas vezes recorrem a ela como auxílio para resolver os problemas enfrentados em sala de aula, ou ainda buscar da melhor forma possível uma formação de qualidade.

Nesse contexto, a discussões apresentadas nesta pesquisa sobre a relação teoria e prática na formação docente, nos levam a uma reflexão sobre como alguns professores de cursos de nível técnico da área da saúde relacionam, em sua formação, a questão da teoria e prática, o que pensam sobre esses conceitos e como trabalham na sua formação.

Dessa forma, foi possível identificar, com base nas análises apresentadas pelos participantes do trabalho que a maioria utiliza da teoria e da prática na sua formação docente e reconhecem de sua importância na qualificação profissional para atender as demandas necessárias a formação dos seus alunos.

\section{REFERÊNCIAS BIBLIOGRÁFICAS}

1. ALARCÃO, Isabel. Professor - Investigador: que sentido que formação. In Cadernos de formação de professores n. 1 , p. 21 -30 . 2001.

2. CANDAU, Vera Maria; LELIS, Isabel Alice. A Relação Teoria-Prática na Formação do educador. In: CANDAU, V.M (Org.). Rumo a uma Nova Didática. 10 ed. Petrópolis: Vozes. 1999. p.56-72. ISBN 978-85-32604-34-0

3. BRASIL. Formação de professores para educação profissional e tecnológica. Brasília: Instituto Nacional de Estudos e Pesquisas Educacionais Anísio Teixeira (INEP), 2008, 304p (Coleção Educação Superior em Debate, v. 8). Disponível em: <http://www.oei.es/pdfs/formacion_profesores_educacion_profesional_inep.pdf. > Acesso em: 18 fev. 2013.

4. __ Lei de Diretrizes e Bases da Educação Nacional. Brasília, 2010. Disponível em < Acesso em: http://portal.mec.gov.br/arquivos/pdf/ldb.pdf> Acesso em: 14 jun.2014.

5. Gil, Antonio Carlos. Métodos e técnicas de pesquisa social. 6. ed. - São Paulo : Atlas, 2008.

6. GIRON. Graziela Rossetto. A influência da política, do planejamento e da gestão educacional na formação social do indivíduo. Disponível em: $<$ https://www.google.com.br/webhp?sourceid=chrome-instant\&ion=1\&espv=2\&ie=UTF$8 \#$ safe $=$ active $\& q=A+I N F L U \% C 3 \% 8 A N C I A+D A+P O L \% C 3 \% 8 D T I C A \% 2 C+D O+P L A N E J A M E N T O$ +E+DA+GEST\%C3\%830+EDUCACIONAL+NA+FORMA\%C3\%87\%C3\%830+SOCIAL+DO+INDI V\%C3\%8DDUO+Graziela+Rossetto+Giron 26/07/2016. 
7. KOLLER. Cláudio; SOBRAL, Francisco. A construção da identidade nas escolas agrotécnicas federais a trajetória da COAGRI AO CONEAF. Educação profissional e tecnológica no Brasil contemporâneo: desafios, tensões e possibilidades. Porto Alegre: Artmed, p,226.2010.

8. KUENZER, Acácia Zeneida e GRABOWSKI, Gabriel. Educação profissional: desafios para a construção de um projeto para os que vivem do trabalho. Perspectiva [online]. 2006, vol.24, n.01 [citado 2014-12-18], pp. 297-318. Disponível em: $<$ http://educa.fcc.org.br/scielo.php?script=sci_arttext\&pid=S0102$54732006000100013 \&$ Ing=pt\&nrm=iso $>$. ISSN 0102-5473.

9. LAKATOS, Eva Marconi. Fundamentos de metodologia científica. São Paulo: Atlas, 2003.

10. MACHADO, LUCILIA REGINA SOUZA. Diferenciais inovadoras na formação de professores para a Educação Profissional. In:MOURA, Dante Henrique. (Org.). Produção de conhecimento, políticas públicas e formação docente em educação profissional. Campina SP, Mercado de Letras, 2013.

11. MOLL, JAQUELINE (Org.) \& Cols. In. CARVALHO, Olgamir Francisco. Dualismo versus congruência. Diálogo entre o novo método brasileiro para formação profissional e o modelo didático ESC (Experiencial, Científico e Construtivista). Educação profissional e tecnológica no Brasil contemporâneo: desafios, tensões e possibilidades. Porto Alegre: Artmed, 2010.

12. MOURA, Dante Henrique. (Org.) Produção de conhecimento, políticas públicas e formação docente em educação profissional: Ensino médio e educação profissional no Brasil nos anos 2000: Movimentos contraditórios. Campina SP, Mercado de Letras, 2013.

13. PADILHA, Paulo Roberto. Currículo intertranscultural: Novos itinerários para a educação. São Paulo, Cortez: Instituto Paulo Freire, vol.8, 2004.

14. PEREIRA, Luiz Augusto Caldas. A formação de professores e a capacitação de trabalhadores. [s.d ].

15. TIMOTEO. Rosalba Pessoa de Souza . LIBERALINO. Francisca Nazaré . Reflexões acerca do fazer pedagógico a partir de referências e diretrizes educacionais para a formação em enfermagem. Rev Bras Enferm, Brasília (DF) 2003 jul/ago;56(4):358-360. Disponível em: http://www.scielo.br/scielo.php?script=sci_arttext\&pid=S0034-71672003000400008 . 